\title{
Resting energy expenditure and substrate oxidation rates correlate to temperature and outcome after cardiac arrest - a prospective observational cohort study
}

Ulrike Holzinger $^{1 *}$, Richard Brunner ${ }^{1}$, Heidrun Losert ${ }^{2}$, Valentin Fuhrmann ${ }^{3}$, Harald Herkner ${ }^{2}$, Christian Madl $^{1}$, Fritz Sterz ${ }^{2}$ and Bruno Schneeweiß ${ }^{1}$

\begin{abstract}
Introduction: Targeted temperature management improves outcome after cardiopulmonary resuscitation. Reduction of resting energy expenditure might be one mode of action. The aim of this study was to correlate resting energy expenditure and substrate oxidation rates with targeted temperature management at $33^{\circ} \mathrm{C}$ and outcome in patients after cardiac arrest.
\end{abstract}

Methods: This prospective, observational cohort study was performed at the department of emergency medicine and a medical intensive care unit of a university hospital. Patients after successful cardiopulmonary resuscitation undergoing targeted temperature management at $33^{\circ} \mathrm{C}$ for 24 hours with subsequent rewarming to $36^{\circ} \mathrm{C}$ and standardized sedation, analgesic and paralytic medication were included. Indirect calorimetry was performed five times within $48 \mathrm{~h}$ after cardiac arrest. Measurements were correlated to outcome with repeated measures ANOVA, linear and logistic regression analysis.

Results: In 25 patients resting energy expenditure decreased 20 (18 to 27$) \%$ at $33^{\circ} \mathrm{C}$ compared to $36^{\circ} \mathrm{C}$ without differences between outcome groups (favourable vs. unfavourable: 25 (21 to 26) vs. 21 (16 to 26); $P=0.5$ ). In contrast to protein oxidation rate (favourable vs. unfavourable: 35 (11 to 68) g/day vs. 39 (7 to 75) g/day, $P=0.8$ ) patients with favourable outcome had a significantly higher fat oxidation rate (139 (104 to 171) g/day vs. 117 (70 to 139$) \mathrm{g} /$ day, $P<0.05)$ and a significantly lower glucose oxidation rate (30 ( -34 to 88$) \mathrm{g} /$ day vs. 77 (19 to 138$)$ $\mathrm{g} /$ day; $P<0.05)$ as compared to patients with unfavourable neurological outcome.

Conclusions: Targeted temperature management at $33^{\circ} \mathrm{C}$ after cardiac arrest reduces resting energy expenditure by $20 \%$ compared to $36^{\circ} \mathrm{C}$. Glucose and fat oxidation rates differ significantly between patients with favourable and unfavourable neurological outcome.

Trial registration: Clinicaltrials.gov NCT00500825. Registered 11 July 2007.

\footnotetext{
* Correspondence: ulrike.holzinger@meduniwien.ac.at

'Department of Medicine III, Division of Gastroenterology and Hepatology, ICU 13H1, Medical University of Vienna, Waehringer Guertel 18-20, Vienna 1090, Austria

Full list of author information is available at the end of the article
}

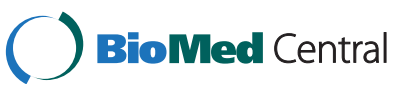

(c) 2015 Holzinger et al.; licensee BioMed Central. This is an Open Access article distributed under the terms of the Creative Commons Attribution License (http://creativecommons.org/licenses/by/4.0), which permits unrestricted use, distribution, and reproduction in any medium, provided the original work is properly credited. The Creative Commons Public Domain Dedication waiver (http://creativecommons.org/publicdomain/zero/1.0/) applies to the data made available in this article, unless otherwise stated. 


\section{Introduction}

Targeted temperature management improves neurological outcome after cardiopulmonary resuscitation (CPR) although the target temperature is matter of discussion [1-3]. According to the guidelines of the European Resuscitation Council and the American Heart Association comatose patients resuscitated after cardiac arrest should undergo therapeutic hypothermia with a target temperature of 32 to $34^{\circ} \mathrm{C}$ for 24 hours $[4,5]$.

Reduction of resting energy expenditure (REE) might be one of the possible mechanisms underlying the protective effects of hypothermia provided that the counterregulatory mechanism of shivering is prevented by the use of adequate medication [6,7]. The extent of REE reduction is expected to be approximately $8 \%$ per ${ }^{\circ} \mathrm{C}[6,7]$. In critically ill patients with fever, indirect calorimetry showed REE reduction by 6 to $12 \%$ per ${ }^{\circ} \mathrm{C}$ using external cooling $[8,9]$. In patients with traumatic brain injury no reduction of $\mathrm{REE}$ was found below $35^{\circ} \mathrm{C}$ in contrast to temperatures higher than $35^{\circ} \mathrm{C}$ [10].

Studies evaluating the influence of hypothermia on substrate metabolism are rare. Most of them are animal investigations or studies including non-sedated humans and can, therefore, not be compared to the patients in the present study [11-14].

Influence of therapeutic hypothermia on REE and substrate metabolism in patients resuscitated after cardiac arrest has not been investigated so far. Therefore, the objective of this study was the investigation of the correlation of REE and substrate oxidation rates with temperature management at $33^{\circ} \mathrm{C}$ after cardiac arrest and outcome.

\section{Methods}

This was a prospective, observational study using indirect calorimetric assessments in patients undergoing targeted temperature management at $33^{\circ} \mathrm{C}$ after cardiac arrest as part of routine clinical care according to established protocols in our Department of Emergency Medicine [15]. The study was investigator-initiated and investigatordriven. The study protocol conformed to the ethical guidelines of the Declaration of Helsinki and was approved by the research ethics committee of the Medical University of Vienna. According to the Austrian law the Institutional Review Board for human studies approved the protocol with an exception from informed consent guidelines. None of the patients ended up having consent refused by next of kin or recovered patients after they awoke and were contacted.

The study was performed in the intensive care units (ICUs) of the Department of Medicine III, Division of Gastroenterology and Hepatology (Intensive Care Unit $13 \mathrm{~h} 1$ ) and the Department of Emergency Medicine at the Medical University Hospital of Vienna.
Patients were eligible for inclusion in the study if they were older than 18 years of age and hospitalized within 6 hours after resuscitation from cardiac arrest.

\section{Treatment}

General

Patients were stabilized according to the treatment protocols [15]. Standards of post-resuscitation care included airway management and mechanical ventilation, treatment of haemodynamic instabilities and arrhythmias, blood glucose control and temperature control with a temperature probe in the oesophagus. For every patient, age, sex, presumed cause of cardiac arrest, initial rhythm, duration of $\mathrm{CPR}$, comorbidities as well as laboratory data and medication were documented. Patients were followed up at 1, 6 and 12 months according to the Utstein Style using the following scoring instruments: Glasgow coma scale (GCS), cerebral performance category (CPC), and overall performance category (OPC) [16].

\section{Targeted temperature management}

All patients were cooled using either Alsius Coolgard $3000^{\mathrm{mm}}$ (Zoll Medical Corporation., Chelmsford, MA, USA) or Arctic Sun ${ }^{\mathrm{Tm}}$ (Medivance, Inc., Louisville, CO, USA) with the maximal cooling rate until the target core temperature of $33^{\circ} \mathrm{C}$. The cooling period lasted 24 hours and rewarming was performed with a rate of $0.4^{\circ} \mathrm{C}$ /hour until a core temperature of $36^{\circ} \mathrm{C}$ was reached.

\section{Medication}

All patients received sedation and analgesia with midazolam and fentanyl as well as muscle paralysis with rocuronium according to the therapeutic standards at the Department of Emergency Medicine at the Medical University of Vienna [15]. Depth of neuromuscular blockade was assessed using the TOF Watch ${ }^{\text {тм }}$ SX (Organon Medical Systems, Roseland, NJ, USA), which monitors neuromuscular transmission during surgery or intensive care by means of acceleromyography. Two electrodes are placed above the ulnar nerve and the response to the nerve stimulation is measured by using a small piezoelectrode acceleration transducer distally placed on the volar side of the thumb. Four pulses are given and the measuring is based upon a ratio of the amplitude of the fourth evoked mechanical response to the first one. Sedation as well as analgesic and paralytic medication was stopped after rewarming at $36^{\circ} \mathrm{C}$. Patients did not receive any intravenous fluids containing dextrose during the study period. As preferred, crystalloid Ringer lactate solution was used. Some patients received isotonic saline solution. Medications were dissolved or diluted using isotonic saline or Ringer lactate solution or distilled water as specified. 


\section{Indirect calorimetry}

Respiratory gas exchange was measured by computerized open-circuit indirect calorimetry (Deltatrac ${ }^{\mathrm{Tn}}$ II Metabolic Monitor, Datex-Ohmeda Instruments, Helsinki, Finland) as previously described $[17,18]$. Oxygen consumption and carbon dioxide production were measured in 1-minute intervals and the average of a 30-minute period was calculated. The paramagnetic oxygen sensor allows inspiratory oxygen concentration up to $65 \%$ according to the manufacturer. Measurements were performed over a period of 1 hour. Data for further calculation were taken from the second half of the measurement to assure steady state conditions. Ventilator setting remained unchanged at least half an hour before and during measurement. Patients did not receive any form of caloric intake during the cooling and rewarming period. They underwent an 8-hour fasting period before the last calorimetry. To get an overview about REE and substrate metabolism in the different phases of post-resuscitation care (stable cooling phase, passive rewarming, active rewarming, rewarmed stable phase) indirect calorimetry was performed five times: 12 to 24 hours after achieving the target temperature of $33^{\circ} \mathrm{C}$ (stable phase), during rewarming at a temperature of $34.5^{\circ} \mathrm{C}$, $36^{\circ} \mathrm{C}, 36.5$ to $37.5^{\circ} \mathrm{C}$ and 48 hours after cardiac arrest. Sedation as well as analgesic and paralytic medication was stopped after the measurement at $36^{\circ} \mathrm{C}$.

\section{Calculations}

REE was expressed in $\mathrm{kJ}$ (Kcal) $/$ day $/ \mathrm{m}^{2}$ body surface area. REE and oxidation rates for glucose, fat, and protein were calculated according to Ferrannini et al. [19]. It was assumed that for each $1 \mathrm{~g}$ nitrogen produced, $5.923 \mathrm{~L}$ oxygen were consumed and $4.754 \mathrm{~L}$ carbon dioxide were produced (respiratory quotient for protein: 0.803) [20]. For calculation of urea nitrogen appearance rates, changes in plasma urea concentration were taken into account (measurement at the beginning and at the end of each calorimetry) [21]. Urine production was measured along with each calorimetric measurement. Urinary urea nitrogen was measured colorimetrically [22]. The protein oxidation rate $(\mathrm{g} / \mathrm{d})$ was calculated as $6.25 \times$ 24-hour urea nitrogen production (g/d) [23].

\section{Statistical analysis}

Due to the pilot study character and data characteristics we regarded a sample size of 25 patients to be feasible and adequate to yielding sufficient precision of our estimates. Continuous data are presented as median and 25 to $75 \%$ interquartile range (IQR) or mean \pm standard deviation as appropriate by distribution. Categorical data are presented as count and relative frequency. Twentyfive independent patients each contributed data from five occasions defined by certain temperature levels. Accordingly, we treated data as panel data. Generally linear effects were assessed across categories of temperature and not across actual temperature on a ${ }^{\circ} \mathrm{C}$ scale.

To assess the influence of temperature on metabolic variables we used linear random intercept models. The independent variable was the metabolic variable, temperature was modelled as linear variable, and the clustering variable was a patient identifier. To assess a potential relation between metabolic variables and sedation we grouped data according to temperature $\leq 36^{\circ} \mathrm{C}$ and $>36^{\circ} \mathrm{C}$, because sedation protocols were linked to core temperature. We then repeated the above regression by replacing temperature by the dichotomous variable sedation.

To assess a potential association between metabolic variables and neurological outcome we calculated temperature level-wise independent $t$ tests adjusted for multiplicity by the Bonferroni method. We then developed a logistic random intercept model where favourable neurological outcome was the independent variable, and each one of the metabolic variables was entered as predictor, whilst allowing for the panel structure of the data.

To assess the influence of norepinephrine dose on metabolic variables we used linear random intercept regression models with each metabolic variable as independent variable, and norepinephrine therapy as predictor allowing for clustering as described above. Likewise, we investigated the influence of temperature on insulin dose (U/hour) and serum creatinine $(\mathrm{mg} / \mathrm{dl})$. Both variables were handled as continuous outcomes. We also tested for an interaction of norepinephrine on the relation between neurological outcome and metabolic variables.

To reassess our models we employed standard regression models using robust standard errors. Results from both approaches were comparable for all calculations. For data management we used Excel 2008 for Mac (Microsoft Corporation, Redmond, WA, USA), for data analysis we used Stata 9.0 for Mac (Stata Corp, College Station, TX, USA). Generally a two-sided $P$ value less than 0.05 was considered statistically significant.

\section{Results}

Patient characteristics and outcome are given in Table 1. The median sequential organ failure assessment (SOFA) score was 10 (9.25 to 10.75$)$ in patients with unfavourable neurological outcome and 10 (9 to 11) in patients with favourable neurological outcome. Targeted temperature management was performed using surface cooling in 15 patients and intravascular cooling in 10 patients. We compared C-reactive protein, fibrinogen and leukocyte count as markers of inflammation as well as platelet count, D-dimer, prothrombin time and activated partial thromboplastin time as markers of coagulation between the patient groups undergoing different cooling methods. No differences were observed between the two different cooling methods (data not shown). Mean train-of- 
Table 1 Patients' characteristics and outcome data $(n=25)$

\begin{tabular}{ll}
\hline Age (years) & $\mathbf{6 1 \pm 1 4}$ \\
\hline BMI $\left(\mathrm{kg} / \mathrm{m}^{2}\right)$ & $26 \pm 4$ \\
$\mathrm{BSA}\left(\mathrm{m}^{2}\right)$ & $1.9 \pm 0.2$ \\
Female - no (\%) & $6(24)$ \\
Reason for CA - no (\%) & $15(60)$ \\
$\mathrm{MCl}$ & $6(24)$ \\
Rhythm disorder & $4(16)$ \\
Others & \\
Initial cardiac rhythm - no (\%) & $21(84)$ \\
VFNT & $4(16)$ \\
Asystole/PEA & $25(14-32)$ \\
CA to ROSC (min) & \\
Neurological outcome at 12 months - no (\%) \\
CPC 1-2 (favourable) & $15(60)$ \\
CPC 3-5 (unfavourable) & $10(40)$ \\
Survival - no (\%) & $16(64)$ \\
\hline
\end{tabular}

Values are expressed as absolute numbers and percentage and as mean value \pm standard deviation or median with 25 to $75 \%$ quartiles. Others comprise one intoxication with consecutive apnea, one high-voltage accident, one pulmonary embolism and one unknown reason. BMl, body mass index; BSA, body surface area; $\mathrm{CA}$, cardiac arrest; $\mathrm{MCl}$, myocardial infarction; $\mathrm{VF}$, ventricular fibrillation; $\mathrm{VT}$, ventricular tachycardia; PEA, pulseless electric activity; ROSC, return of spontaneous circulation; CPC, cerebral performance category.

four (TOF) value was 0.114 indirect calorimetric measurements were performed. Two patients died after the first measurement and in one patient indirect calorimetry had to be stopped after the third measurement due to technical failure of the monitor. In one patient the last measurement could not be performed because of a fraction of inspired oxygen $\left(\mathrm{FiO}_{2}\right)$ level of $100 \%$ due to adult respiratory distress syndrome after aspiration. In case of premature study termination collected data were used for analysis until the patient left the study.

Time points of indirect calorimetric measurements resulted in temperature categories of $1.5^{\circ} \mathrm{C}$ below $36^{\circ} \mathrm{C}$ and temperature categories of $0.8^{\circ} \mathrm{C}$ above $36^{\circ} \mathrm{C}$ (as presented in Figures 1 and 2 and Table 2). The overall mean oxygen consumption $\left(\mathrm{VO}_{2}\right)$ was $241 \mathrm{ml} / \mathrm{min}$ with a range from 125 to $662 \mathrm{ml} / \mathrm{min}$ over all measurements. Within individuals the mean standard deviation (SD) was $13 \mathrm{ml} /$ min (5\% of the mean) representing measurement variability. Between individuals, SD was $68 \mathrm{ml} / \mathrm{min}$ on average (28\% of the mean) representing the variability between the patients. During the initial stable conditions (with sedation, analgesics and paralysis at $33^{\circ} \mathrm{C}$ ) variability was smaller: overall range 125 to $476 \mathrm{ml} / \mathrm{min}$. Within-individual SD was $9.00 \mathrm{ml} / \mathrm{min}(4.5 \%$ of the mean). The between-individual SD was $52.13 \mathrm{ml} / \mathrm{min}$ (26\% of the mean).

Calorimetric measurements and substrate metabolism of all patients are given in Table 2. Negative glucose values reflect net gluconeogenesis whereas positive values indicate glucose oxidation.

REE showed a reduction of 20 (18 to 27 ) \% at $33^{\circ} \mathrm{C}$ compared to $36^{\circ} \mathrm{C}$ without differences between outcome groups (favourable vs. unfavourable: 25 (21 to 26) vs. 21 (16 to 26); $P=0.5$ ) and a linear relation to temperature alterations $\left(297 \mathrm{~kJ}(71 \mathrm{kcal}) / \mathrm{m}^{2} /{ }^{\circ} \mathrm{C}\right.$ category; $\left.P<0.0001\right)$ (Figure 1).

Fat oxidation rate showed a temperature dependency (10 g/day $/{ }^{\circ} \mathrm{C}$ category; $\left.P<0.0001\right)$, while glucose and

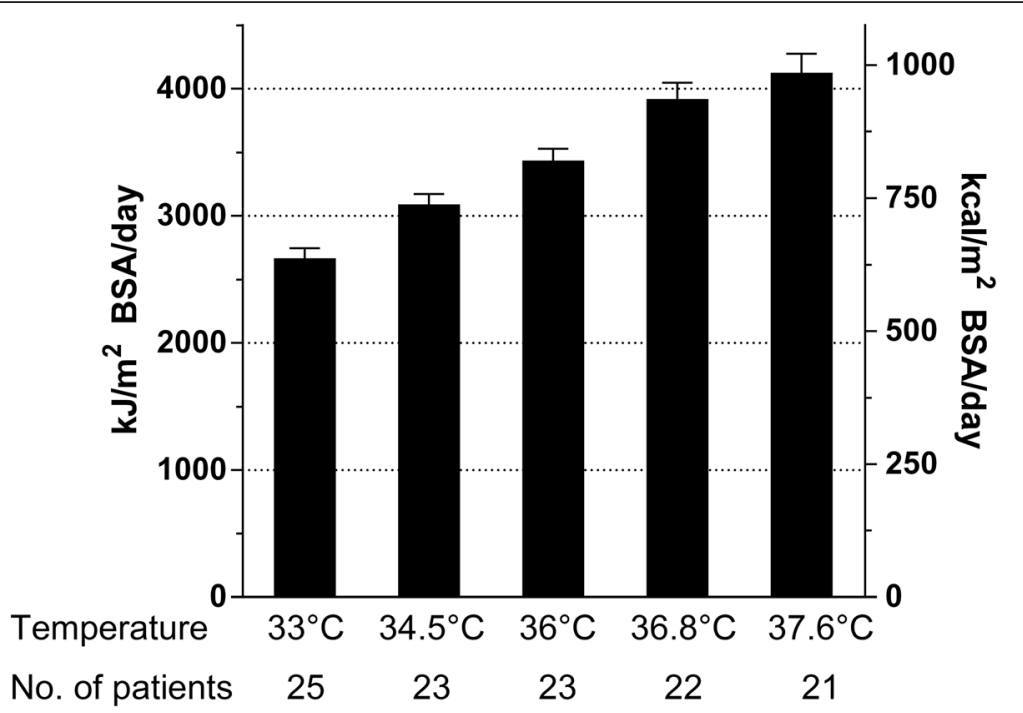

Figure 1 Resting energy expenditure (REE) of all patients measured with indirect calorimetry at the different temperatures. REE is given in $\mathrm{kJ} / \mathrm{m}^{2}\left(\mathrm{kcal} / \mathrm{m}^{2}\right)$ of body surface area (BSA)/day. A linear relation between REE and temperature was detected $\left(297 \mathrm{~kJ}(71 \mathrm{kcal}) / \mathrm{m} 2 /{ }^{\circ} \mathrm{C} \mathrm{category}\right.$; $P<0.0001)$. 


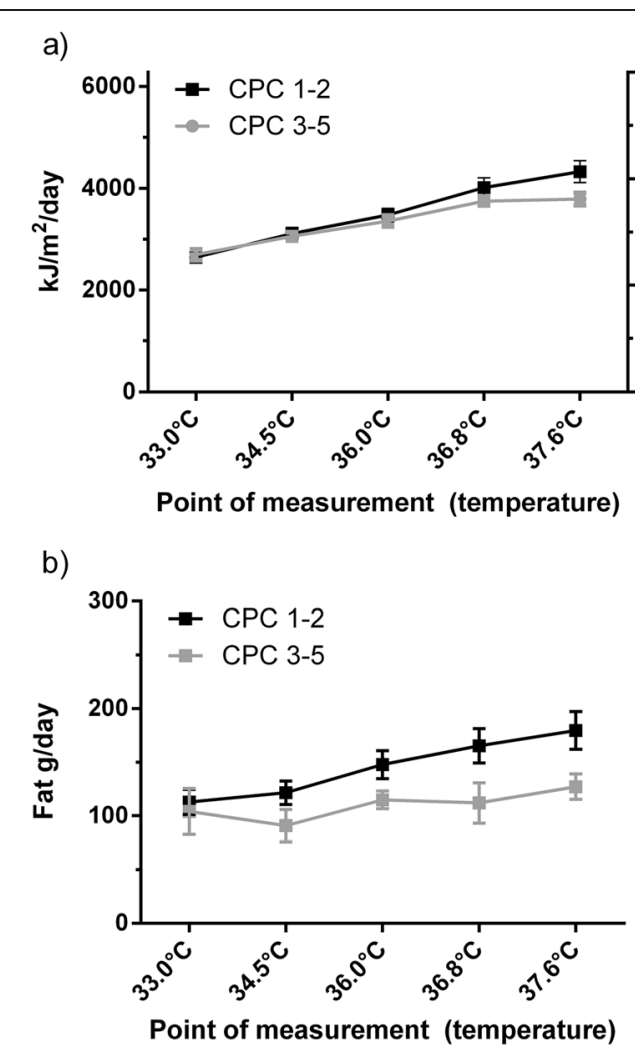

c)

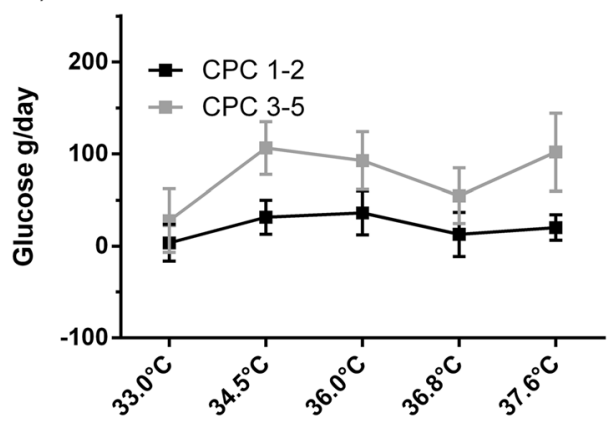

Point of measurement (temperature)

d)

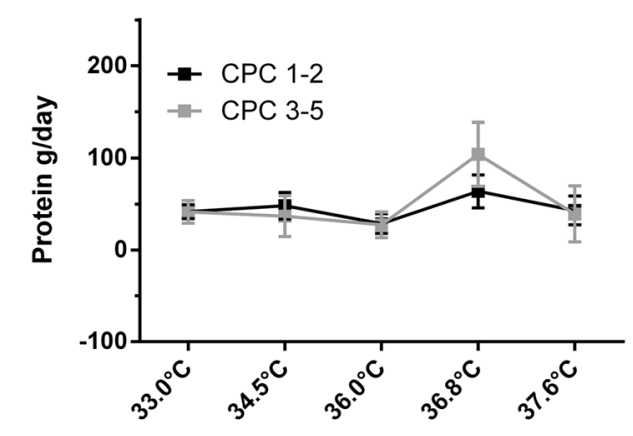

Point of measurement (temperature)
Figure 2 Changes in metabolic variables during the whole study period assessed with indirect calorimetry at the defined time points. Comparison of patients with favourable neurological outcome (CPC 1 to 2) with unfavourable neurological outcome (CPC 3 to 5): black dots $\bullet$, favourable neurological outcome; grey squares -, unfavourable neurological outcome, error bars indicate standard deviation. (a) Linear regression of REE did not show a difference between patients with favourable and unfavourable neurological outcome $(P=0.2)$. (b) Linear regression of fat oxidation rates revealed a significant difference between patients with favourable and unfavourable neurological outcome $(P<0.05)$. (c) Linear regression of glucose oxidation rates revealed a significant difference between patients with favourable and unfavourable neurological outcome $(P<0.05)$. (d) Linear regression of protein oxidation rates did not show a difference between patients with favourable and unfavourable neurological outcome $(P=0.8)$. CPC, cerebral performance category; REE, resting energy expenditure.

protein oxidation rates were not significantly dependent from temperature ( $P=0.07$ or $P=0.06$, respectively).

In contrast to protein oxidation rate (favourable vs. unfavourable outcome: 35 (11 to 68 ) g/day vs. 39 (7 to 75 ) g/day, $P=0.8$ ) patients with favourable outcome had a significantly higher fat oxidation rate (139 (104 to 171) g/day vs. 117 (70 to 139$) \mathrm{g} /$ day, $P<0.05)$ and a significantly lower glucose oxidation rate (30 ( -34 to 88$)$ g/day vs. 77 $(19$ to 138$) \mathrm{g} /$ day; $P<0.05)$ as compared to patients with unfavourable neurological outcome (Figure 2).

REE was not associated with neurological outcome (odds ratio (OR) $0.88,95 \%$ confidence interval (CI) 0.63 to 1.22 of favourable neurological outcome for each unit increase in REE quartile, $P=0.4$; Figure 2). Probability of unfavourable neurological outcome increased by $69 \%$ (OR 1.69, 95\% CI 1.15 to $2.49 ; P<0.01$ ) with every increase of glucose oxidation rate from one quartile to the next. Probability of unfavourable neurological outcome decreased by $38 \%$ (OR $0.62,95 \%$ CI 0.44 to $0.87 ; P<0.01$ ) with every increase of fat oxidation rate from one quartile to the next.

For all patients dosage of sedation and analgesic medication (midazolam, fentanyl), neuromuscular blocker (rocuronium) and norepinephrine as well as insulin at the different measurement points is given in the electronic supplementary file (Table S1 in Additional file 1). One patient received dobutamine during the rewarming period (measurement 2, 3 and 4). Another patient received levosimendan during the first two measurements. Although both medications might influence metabolism, subgroup analysis was not possible due to the small number of patients.

Insulin therapy was not associated with outcome $(P=$ $0.3)$, REE $(P=0.7)$ or substrate oxidation rates (glucose: $P=0.2$; fat: $P=0.9$; protein: $P=0.7$ ).

Sedation, analgesia and neuromuscular blockade (NMB) rates were strongly associated with REE reduction; (967 kJ (231 $\mathrm{kcal}) / \mathrm{day} / \mathrm{m}^{2}$ (95\% CI $181(758)$ to $280(1,172)$; 
Table 2 Substrate metabolism of all patients at different calorimetric measurement

\begin{tabular}{llllll}
\hline \multicolumn{7}{l}{ Points of measurement $\left({ }^{\circ} \mathbf{C}\right)$} & & & \\
\cline { 2 - 6 } & $\mathbf{3 3}$ & $\mathbf{3 4 . 5}$ & $\mathbf{3 6}$ & $\mathbf{3 6 . 8}$ & $\mathbf{3 7 . 6}$ \\
\hline $\mathrm{RQ}$ & $0.72(0.69-0.83)$ & $0.76(0.72-0.82)$ & $0.76(0.74-0.79)$ & $0.75(0.72-0.79)$ & $0.75(0.73-0.78)$ \\
$\mathrm{VO} 2(\mathrm{ml} / \mathrm{min})$ & $187(147-220)$ & $215(179-248)$ & $243(191-266)$ & $264(221-313)$ & $259(246-311)$ \\
$\mathrm{VCO}(\mathrm{ml} / \mathrm{min})$ & $136(122-151)$ & $162(138-187)$ & $185(148-199)$ & $193(173-232)$ & $198(189-234)$ \\
$\mathrm{pH}$ & $7.36(7.29-7.41)$ & $7.36(7.31-7.40)$ & $7.37(7.32-7.40)$ & $7.35(7.26-7.40)$ & $7.34(7.29-7.43)$ \\
Lactate $(\mathrm{mmol} / \mathrm{l})$ & $1.4(1.0-2.0)$ & $1.4(1.0-1.9)$ & $1.2(0.9-1.7)$ & $1.1(0.9-1.4)$ & $1.0(0.9-1.6)$ \\
UNP $(\mathrm{g} / \mathrm{d})$ & $6.1(2.3-9.1)$ & $4.2(1.2-12.1)$ & $3.4(1.9-8.8)$ & $9.7(4.7-22.1)$ & $4.4(0.5-16.3)$ \\
$\mathrm{Glucose}(\mathrm{g} / \mathrm{d})$ & $-5(-50-92)$ & $79(-13-113)$ & $67(14-106)$ & $36(-27-86)$ & $50(5-105)$ \\
Fat $(\mathrm{g} / \mathrm{d})$ & $125(55-154)$ & $118(69-137)$ & $128(109-164)$ & $153(106-175)$ & $140(119-178)$ \\
Protein $(\mathrm{g} / \mathrm{d})$ & $38.3(14.2-57.1)$ & $25.9(7.7-75.3)$ & $21.4(11.9-55.3)$ & $60.4(29.6-137.8)$ & $27.5(2.9-101.9)$ \\
Creatinine $(\mathrm{mg} / \mathrm{dl})$ & $0.96(0.65-1.05)$ & $0.87(0.70-0.99)$ & $0.92(0.79-1.05)$ & $0.91(0.73-1.07)$ & $0.98(0.76-1.14)$ \\
\hline
\end{tabular}

Negative glucose values reflect net gluconeogenesis whereas positive values indicate glucose oxidation. Additionally arterial blood ph and lactate are given as marker of aerobe metabolism and creatinine as marker of renal function. Values are expressed as median with 25 to $75 \%$ quartiles. $\mathrm{RQ}_{1}$, respiratory quotient; $\mathrm{O}_{2}$, oxygen consumption; $\mathrm{VCO}_{2}$, carbon dioxide production; UNP, urea nitrogen production.

$P<0.0001)$. Likewise fat oxidation rate was reduced by $34 \mathrm{~g} / \mathrm{d}(95 \%$ CI 14 to $54 ; P<0.01)$ during sedation. Glucose oxidation rate $(P=0.9)$ and protein oxidation $(P=0.06)$ were not significantly associated with sedation.

Even though we did not find an association between norepinephrine therapy and $\operatorname{REE}(P=0.7)$ or protein oxidation rate $(P=0.6)$, norepinephrine therapy was associated with increased glucose oxidation rate $(P<0.05)$ and reduced fat oxidation rate $(P<0.05)$. However, there was no significant interaction of norepinephrine on the relation between neurological outcome and metabolic variables. Norepinephrine therapy was not associated with outcome $(P=0.7)$.

Temperature was not associated with insulin therapy $(P=0.6)$ or serum creatinine levels $(P=0.8)$. We did not find an association between outcome and serum creatinine levels $(P=0.6)$.

Dosage of all administered medications and blood glucose values at different calorimetric measurements are given in the Table S1 in Additional file 1 for all patients.

\section{Discussion}

Our study showed that in patients after cardiac arrest and successful return of spontaneous circulation undergoing targeted temperature management at $33^{\circ} \mathrm{C}$ REE was reduced (20\% (18 to $27 \%)$ ) compared to $36^{\circ} \mathrm{C}$ with a linear relation to temperature alterations but without differences between outcome groups. Besides temperature, sedation, analgesia and NMB were associated with a REE reduction.

Only fat oxidation rate was associated with temperature, sedation and analgesia. Glucose oxidation rates and fat oxidation rates were significantly different between patients with favourable and unfavourable neurological outcome. An interaction between norepinephrine therapy, neurological outcome and metabolic variables could be excluded. Use of medication (sedatives, analgetics, neuromuscular blockers, insulin and norepinephrine) was not different between patients with favourable and unfavourable neurological outcome.

The effect of cooling on REE has already been described. In hyperthermic patients cooling was able to reduce REE between 6 and $12 \%$ per $1{ }^{\circ} \mathrm{C}$ temperature reduction depending on sedation, analgesia and NMB $[7,8]$. In neurosurgical patients, a significant reduction of REE by cooling was only detectable above a temperature of $35^{\circ} \mathrm{C}$ using sedation and neuromuscular blockers [10]. Generally, a reduction of 6 to $9 \%$ of REE per $1^{\circ} \mathrm{C}$ decrease in temperature is accepted [6,7]. Our study showed a $6.6 \%$ reduction of REE per $1^{\circ} \mathrm{C}$ decrease at temperatures below $36^{\circ} \mathrm{C}$.

A limitation of our study is that effects of sedation, analgesia, NMB and hypothermia cannot be separated due to the study design. All indirect calorimetric measurements at $36^{\circ} \mathrm{C}$ and below were performed with concomitant sedation, analgesia and NMB.

In surgical ICU patients increasing Ramsay sedation scale using midazolam resulted in a significantly decreased REE and oxygen consumption [24]. NMB in combination with controlled mechanical ventilation was able to reduce oxygen consumption by approximately $20 \%$ [25]. In critically ill children NMB was able to reduce REE by approximately $10 \%$ [26]. We found a median reduction of REE of $20 \%$ in our study in adult patients after cardiac arrest at $33^{\circ} \mathrm{C}$. Our data suggest that effects of sedation, analgesia, $\mathrm{NMB}$ and hypothermia on REE might not be additive. This assumption is supported by another study, which showed that in normothermic patients sedation has a major effect on REE; however, in sedated patients temperature was the main determinant of REE [27].

Due to the chosen medication regimen with continuous midazolam, fentanyl and rocuronium administration during the cooling and the passive rewarming period the 
effect of shivering, which is known to highly influence REE, can be disregarded [28,29].

In our study, patients after cardiac arrest and return of spontaneous circulation (ROSC) with favourable neurological outcome had significantly different fat and glucose oxidation rates compared to patients with unfavourable neurological outcome. An increase in quartiles of fat oxidation rate was associated with favourable and an increase in quartiles of glucose oxidation was associated with unfavourable neurological outcome.

Data on substrate metabolism during hypoxia and hypothermia were only available from animal experiments or experiments with healthy subjects. In six healthy males resting at a temperature of $5^{\circ} \mathrm{C}$, free fatty acid turnover, as well as lipid oxidation and carbohydrate oxidation remarkably increased, however this increase was accompanied by a significant increase in the REE [11]. The increase of REE in this experiment is predominantly caused by shivering and thus is not comparable to our analysis.

Hypoxia seems to be associated with remarkable changes in substrate utilization especially in the brain. In cooled anaesthesized dogs, hypoxic conditions increased glucose utilization in the brain [12]. Further animal experiments showed that glucose transporter (GLUT) 3 expression increases up to nine times both in the affected and non-affected neurons after 48 hours of rat brains under ischaemic conditions [13]. This finding is in accordance with data from a rat model of traumatic brain injury, which showed a 300\% increase of GLUT 3 expression up to 48 hours after the event [14]. In traumatic brain injury, a remarkable increase in glucose utilization of the whole brain (hyperglycolysis) can be found up to 7 days after the trauma $[30,31]$. We therefore hypothesize that in patients with unfavourable neurological outcome increased cerebral glucose utilization was present due to severe hypoxiainduced brain injury during cardiac arrest. We assume that this increase accounted for the elevated glucose oxidation rates measured by indirect calorimetry. Since brain glucose utilization normally accounts for $25 \%$ of whole body glucose metabolism [32], changes in glucose oxidation rates of the brain are obviously detectable by indirect calorimetry evaluating whole body substrate metabolism. We cannot rule out influence of other post-cardiac arrest organ injury, especially liver and kidney, on REE and substrate metabolism in our study patients [33,34]. However apart from brain injury, other organ injury seemed to be equally distributed in both patient groups and, therefore, is improbable of having caused the effect shown in our study.

Norepinephrine therapy was significantly associated with glucose and fat oxidation rates but did not interact with the relation between neurological outcome and metabolic values and was not associated with outcome in the present study. Influence of norepinephrine on fat utilization has already been shown before in healthy subjects [35].

Although hypothermia is associated with increased insulin resistance and glucose intolerance, insulin therapy was not associated with temperature in our study $[6,36]$. Insulin was neither associated with REE nor with substrate oxidation rates. Influence of insulin on substrate oxidation rates and energy expenditure seems to be limited $[37,38]$.

A further limitation of our study is the technique of indirect calorimetry itself, which has the advantage of being non-invasive, however, is prone to multiple errors. Although, measurements were performed according to the manufacturer's instructions and with greatest diligence, errors influencing our results cannot be fully excluded [39]. Using indirect calorimetry, only whole body net balances of substrate metabolism can be described without knowledge of localized substrate oxidation or biosynthesis rates. We can rule out bias of anaerobic metabolic pathways in a substantial way because lactate levels were in the normal range throughout the study period. That is why measurements started in the second half of the 24-hour cooling period, in order to have already achieved stabilized conditions, without anaerobic metabolism.

Besides the small number of patients included, a major limitation of this study is the substantial variability of the measurements of substrate metabolism themselves. The factors that impact substrate metabolism - including the specific blend of organ failures, host global and organ-specific inflammation and function - are multitudinous. Accordingly, we cannot discount the possibility of confounding by variables not measured in this study like interleukin levels or organ-specific substrate metabolism, but our study nonetheless raises an interesting hypothesis for future studies that might control for the most important confounders. Results have to be reproduced and further investigation is necessary to elucidate pathophysiological actions during the post-cardiac arrest period resulting in detectable metabolic differences between patients with favourable and unfavourable neurological outcome.

\section{Conclusions}

Targeted temperature management at $33^{\circ} \mathrm{C}$ after cardiac arrest reduces REE by $20 \%$ with a linear relation to temperature variations. Only fat oxidation rate was temperature dependent. A significant difference in glucose and fat oxidation rates was found between patients with favourable and unfavourable neurological outcome. An increase of fat oxidation rate and a decrease of glucose oxidation rate were associated with favourable outcome. 


\section{Key messages}

- Resting energy expenditure is reduced in patients undergoing targeted temperature management after cardiac arrest irrespective of outcome.

- A difference in fat and glucose oxidation rates can be found between patients with favourable and unfavourable neurological outcome.

\section{Additional file}

\section{Additional file 1: Mean dosage of medications given to patients} with favourable and unfavourable neurological outcome and mean blood glucose at different measurements. All medications are given as median and interquartile range. Blood glucose is given as mean $\pm \mathrm{SD}$.

\section{Abbreviations}

BMI: body mass index; BSA: body surface area; Cl: confidence interval; CPC: Cerebral Performance Category; CPR: cardiopulmonary resuscitation; $\mathrm{FiO}_{2}$ : fraction of inspired oxygen; GCS: Glasgow coma scale; GLUT: glucose transporter; ICU: intensive care unit; IQR: interquartile range; $\mathrm{MCl}$ : myocardial infarction; NMB: neuromuscular blockade; OPC: overall performance category; OR: odds ratio; PEA: pulseless electric activity; REE: resting energy expenditure; ROSC: return of spontaneous circulation; RQ: respiratory quotient; SD: standard deviation; SOFA score: sequential organ failure assessment score; TOF: train-of-four; UNP: urea nitrogen production; $\mathrm{VCO}_{2}$ : carbon dioxide production; $\mathrm{VF}$ : ventricular fibrillation; $\mathrm{VO}_{2}$ : oxygen consumption; VT: ventricular tachycardia.

\section{Competing interests}

The authors declare that they have no competing interests.

\section{Authors' contributions}

$\mathrm{UH}$ and BS conceived of the study. UH, RB, HL, VF and BS made substantial contributions to the conception and design of the work and the analysis and interpretation of data for the work. UH, RB, HL and VF performed the indirect calorimetries. $\mathrm{HH}$ and RB performed the statistical analysis. $\mathrm{UH}$ and BS drafted the work, revising it critically for important intellectual content. FS, $\mathrm{HH}$, and CM made substantial contributions to analysis, interpretation of data for the work and revised it critically for important intellectual content. All authors gave final approval of the version to be published and agreed to be accountable for all aspects of the work in ensuring that questions related to the accuracy and integrity of any part of the work are appropriately investigated and resolved.

\section{Author details}

'Department of Medicine III, Division of Gastroenterology and Hepatology, ICU 13H1, Medical University of Vienna, Waehringer Guertel 18-20, Vienna 1090, Austria. ${ }^{2}$ Department of Emergency Medicine, Medical University of Vienna, Waehringer Guertel 18-20, Vienna 1090, Austria. ${ }^{3}$ Department of Intensive Care, University Medical Center Hamburg-Eppendorf, Martinistraße 52, Hamburg 20246, Germany.

Received: 12 November 2014 Accepted: 4 March 2015

Published online: 29 March 2015

\section{References}

1. The Hypothermia after Cardiac Arrest Study Group. Mild therapeutic hypothermia to improve the neurologic outcome after cardiac arrest. N Engl J Med. 2002;346:549-56.

2. Bernard SA, Gray TW, Buist MD, Jones BM, Silvester W, Gutteridge G, et al. Treatment of comatose survivors of out-of-hospital cardiac arrest with induced hypothermia. N Engl J Med. 2002;346:557-63.

3. Nielsen N, Wetterslev J, Friberg H, TTM Trial Steering Group. Targeted temperature management after cardiac arrest. N Engl J Med. 2013;369:2197-206.
4. Deakin CD, Nolan JP, Soar J, Sunde K, Koster RW, Smith GB, et al. European Resuscitation Council Guidelines for Resuscitation 2010 Section 4. Adult advanced life support. Resuscitation. 2010;81:1305-52.

5. Peberdy MA, Callaway CW, Neumar RW, Geocadin RG, Zimmerman JL, Donnino M, et al. Part 9: post-cardiac arrest care: 2010 American Heart Association Guidelines for Cardiopulmonary Resuscitation and Emergency Cardiovascular Care. Circulation. 2010;2:5768-86.

6. Polderman $\mathrm{KH}$. Mechanisms of action, physiological effects, and complications of hypothermia. Crit Care Med. 2009;37:S186-202.

7. Choi HA, Badjatia N, Mayer SA. Hypothermia for acute brain injurymechanisms and practical aspects. Nat Rev Neurol. 2012;8:214-22.

8. Manthous CA, Hall JB, Olson D, Singh M, Chatila W, Pohlman A, et al. Effect of cooling on oxygen consumption in febrile critically ill patients. Am J Respir Crit Care Med. 1995;151:10-4.

9. Poblete B, Romand JA, Pichard C, König P, Suter PM. Metabolic effects of i.v. propacetamol, metamizol or external cooling in critically ill febrile sedated patients. Br J Anaesth. 1997;78:123-7.

10. Tokutomi T, Morimoto K, Miyagi T, Yamaguchi S, Ishikawa K, Shigemori M. Optimal temperature for the management of severe traumatic brain injury: effect of hypothermia on intracranial pressure, systemic and intracranial hemodynamics, and metabolism. Neurosurgery. 2003;52:102-11.

11. Vallerand AL, Zamecnik J, Jones PJ, Jacobs I. Cold stress increases lipolysis, FFA Ra and TG/FFA cycling in humans. Aviat Space Environ Med. 1999;70:42-50.

12. Hamer J, Wiedemann K, Berlet H, Weinhardt F, Hoyer S. Cerebral glucose and energy metabolism, cerebral oxygen consumption, and blood flow in arterial hypoxaemia. Acta Neurochir. 1978;44:151-60.

13. Urabe T, Hattori N, Nagamatsu S, Sawa H, Mizuno Y. Expression of glucose transporters in rat brain following transient focal ischemic injury. J Neurochem. 1996;67:265-71.

14. Hamlin GP, Cernak I, Wixey JA, Vink R. Increased expression of neuronal glucose transporter 3 but not glial glucose transporter 1 following severe diffuse traumatic brain injury in rats. J Neurotrauma. 2001;18:1011-8.

15. Holzer M. Targeted temperature management for comatose survivors of cardiac arrest. N Engl J Med. 2010;23:1256-64.

16. Prepared by a Task Force of Representatives from the European Resuscitation Council, American Heart Association, Heart and Stroke Foundation of Canada, Australian Resuscitation Council. Recommended guidelines for uniform reporting of data from out-of-hospital cardiac arrest: the 'Utstein style'. Resuscitation. 1991; 22:1-26.

17. Schneeweiss B, Graninger W, Ferenci P, Druml W, Ratheiser K, Steger G, et al. Short-term energy balance in patients with infections: carbohydratebased versus fat-based diets. Metabolism. 1992;41:125-30.

18. Schneeweiss B, Pammer J, Ratheiser K, Schneider B, Madl C, Kramer L, et al. Energy metabolism in acute hepatic failure. Gastroenterology. 1993;105:1515-21.

19. Ferrannini $\mathrm{E}$. The theoretical bases of indirect calorimetry: a review. Metabolism. 1988;37:287-301.

20. Livesey G, Elia M. Estimation of energy expenditure, net carbohydrate utilization, and net fat oxidation and synthesis by indirect calorimetry: evaluation of errors with special reference to the detailed composition of fuels. Am J Clin Nutr. 1988;47:608-28.

21. Maroni BJ, Steinman TI, Mitch WE. A method for estimating nitrogen intake of patients with chronic renal failure. Kidney Int. 1985;27:58-65.

22. Marsh WH, Fingerhut B, Miller $\mathrm{H}$. Automated and manual direct methods for the determination of blood urea. Clin Chem. 1965;11:624-7.

23. Bursztein S, Saphar P, Glaser P, Taitelman U, de Myttenaere S, Nedey R. Determination of energy metabolism from respiratory functions alone. J Appl Physiol. 1977:42:117-9.

24. Terao Y, Miura K, Saito M, Sekino M, Fukusaki M, Sumikawa K. Quantitative analysis of the relationship between sedation and resting energy expenditure in postoperative patients. Crit Care Med. 2003;31:830-3.

25. Manthous CA, Hall JB, Kushner R, Schmidt GA, Russo G, Wood LD. The effect of mechanical ventilation on oxygen consumption in critically ill patients. Am J Respir Crit Care Med. 1995;151:210-4.

26. Vernon DD, Witte MK. Effect of neuromuscular blockade on oxygen consumption and energy expenditure in sedated, mechanically ventilated children. Crit Care Med. 2000;28:1569-71.

27. Bruder N, Raynal M, Pellissier D, Courtinat C, François G. Influence of body temperature, with or without sedation, on energy expenditure in severe head-injured patients. Crit Care Med. 1998;26:568-72. 
28. Sessler DI. Thermoregulatory defense mechanisms. Crit Care Med. 2009:37:S203-10.

29. Badjatia N, Strongilis E, Gordon E, Prescutti M, Fernandez L, Fernandez A, et al. Metabolic impact of shivering during therapeutic temperature modulation: the Bedside Shivering Assessment Scale. Stroke. 2008:39:3242-7.

30. Bergsneider M, Hovda DA, Shalmon E, Kelly DF, Vespa PM, Martin NA, et al. Cerebral hyperglycolysis following severe traumatic brain injury in humans: a positron emission tomography study. J Neurosurg. 1997;86:241-51.

31. Vespa P, Boonyaputthikul R, McArthur DL, Miller C, Etchepare M,

Bergsneider $\mathrm{M}$, et al. Intensive insulin therapy reduces microdialysis glucose values without altering glucose utilization or improving the lactate/pyruvate ratio after traumatic brain injury. Crit Care Med. 2006;34:850-6.

32. Magistretti PJ, Pellerin L, Martin JL. Brain energy metabolism: an integrated cellular perspective. Psychopharmacology: the fourth generation of progress. New York: Raven; 1995. p. 657-70.

33. Kurpad AV, Khan K, Calder AG, Elia M. Muscle and whole body metabolism after norepinephrine. Am J Physiol. 1994;266:E877-84.

34. Schneeweiss B, Graninger W, Ferenci P, Eichinger S, Grimm G, Schneider B, et al. Energy metabolism in patients with acute and chronic liver disease. Hepatology. 1990;11:387-93.

35. Schneeweiss B, Graninger W, Stockenhuber F, Druml W, Ferenci P, Eichinger S, et al. Energy metabolism in acute and chronic renal failure. Am J Clin Nutr. 1990;52:596-601.

36. Hoo-Paris R, Jourdan ML, Wang LC, Rajotte R. Insulin secretion and substrate homeostasis in prolonged hypothermia in rats. Am J Physiol. 1988;255:R1035-40

37. Natali A, Buzzigoli G, Taddei S, Santoro D, Cerri M, Pedrinelli R, et al. Effects of insulin on hemodynamics and metabolism in human forearm. Diabetes. 1990;39:490-500.

38. Welle $\mathrm{S}$, Nair KS, Lockwood D. Effect of a sulfonylurea and insulin on energy expenditure in type II diabetes mellitus. J Clin Endocrinol Metab. 1988;66:593-7.

39. Simonson DC, DeFronzo RA. Indirect calorimetry: methodological and interpretative problems. Am J Physiol. 1990;258:E399-412.

\section{Submit your next manuscript to BioMed Central and take full advantage of:}

- Convenient online submission

- Thorough peer review

- No space constraints or color figure charges

- Immediate publication on acceptance

- Inclusion in PubMed, CAS, Scopus and Google Scholar

- Research which is freely available for redistribution 